\title{
Solitary Fibrous Tumor
}

National Cancer Institute

\section{Source}

National Cancer Institute. Solitary Fibrous Tumor. NCI Thesaurus. Code C7634.

A localized neoplasm of probable fibroblastic derivation. It is characterized by the presence of round to spindle-shaped cells, hylanized stroma formation, thin-walled branching blood vessels, and thin bands of collagen. 